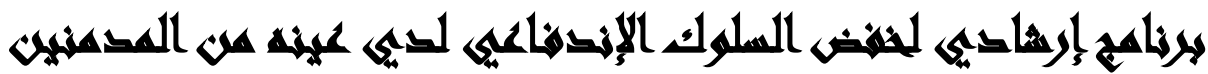

ياسمين حمدي صادق(')- أسماء عبد المنعم ابراهيم(؟)- أحمد حسن محمد الليثي(؟)

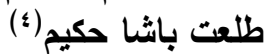

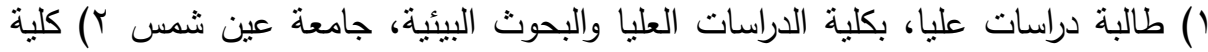

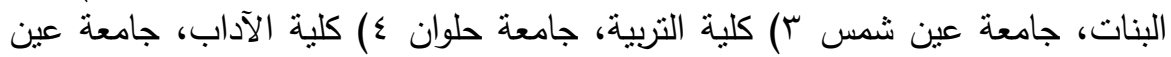

شمس.

\section{lition}

هدفت الدراسة الحالية إعداد برنامج لخفض السلوك الاندفاعى لدى عينة من المدمنين،

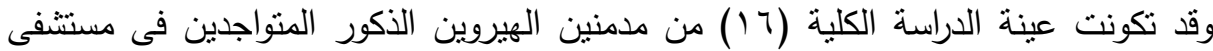

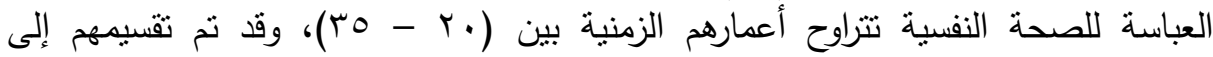

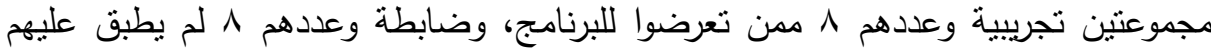

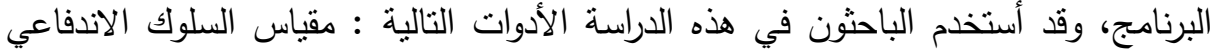
(إعداد الباحثون )، برنامج إرشادي لخفض فئن السلوك الاندفاعي ( إعداد الباحثون)، وقد أستخدم

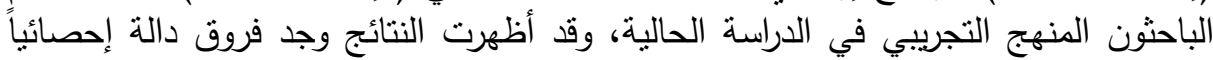

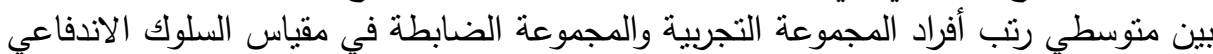
لصالح أفراد المجموعه التجربية بعد تطبيق البرنامج، كما يوجد فربة فروفية دالة فئة إحصائياً بين

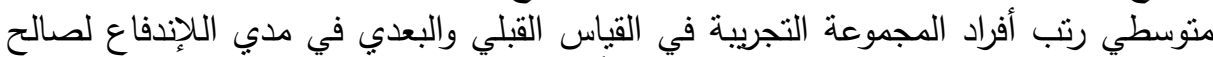

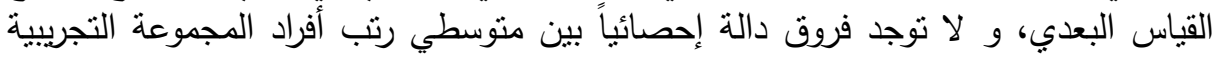

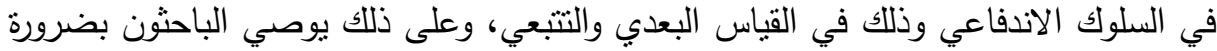

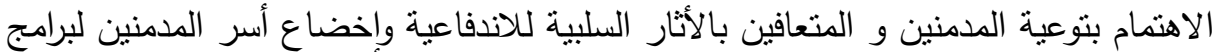

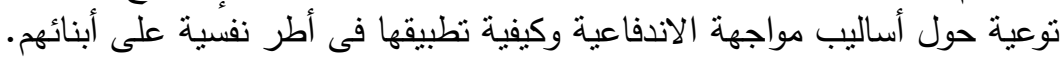
كلمات مفتاحية: (الإدمان، السلوك الانداعة الأناعي)

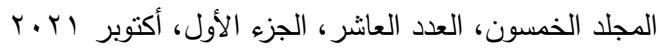

$$
\begin{aligned}
& \text { النزقيم الدولي } \\
& \text { التزقيم الدولي الموحد الإلكتروني 3178-2636 }
\end{aligned}
$$


مجلة العلوم البيئية

كلية الدراسات العليا والبحوث البيئية - جامعة عين شمس البئة

ياسمين حمدي صادق وآخرون

\section{ملهيكة البهمث}

تعد ظاهرة الإدمان من أخطر الظواهر التي تواجه المجتمعات فى الآونة الأخيرة وذلك لأنها تصيب الثباب الذين هم عماد الحضارة، وطاقة المستقبل.

وتختلف نظرة العلماء إلى ظاهرة الإدمان بإختلاف طبيعة المجال نفسه، فالأطباء يرونها علة بيولوجية بمكن التعامل معها طبياً بالعقاقير، بينما بعتبرها علماء النفس اضطراباً سلوكياً

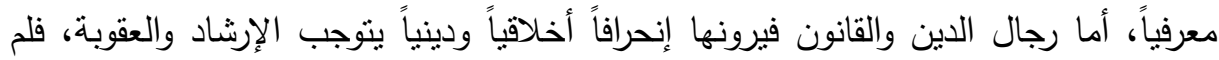
تعد ظاهرة الإدمان بصورتها البسيطة ثنائية الأبعاد الأخلاقية والجنائية، بل إتسعت حدود

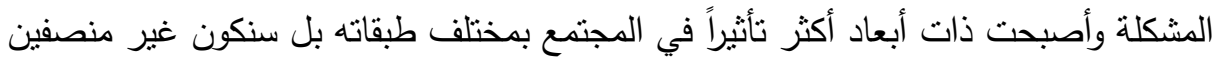
إذا لم نعتبرها مشكلة تهدد المجتمعات المتخلفة والمتقدمة على السواء، وقد اهتمت العديد من الدراسات بمحاولة الكثف عن أسباب الدخول في عالم الإدمان، والظروف النفسية والاجتماعية والثقافية التي تيسر الدخول في الإدمان وكذلك الاهتمام بدراسة العلاقات الإرتباطية بين العديد من الاضطرابات النفسية واضطراب الثخصية وعلاقتها بالإدمان (مجدي أحمد، 1997 : . 0)، ولذلك علينا أن نتصدى لتللك الظاهرة من خلال دراسة العوامل

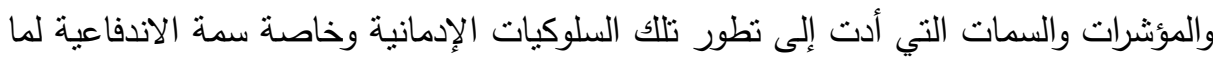

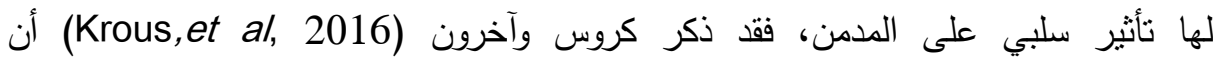

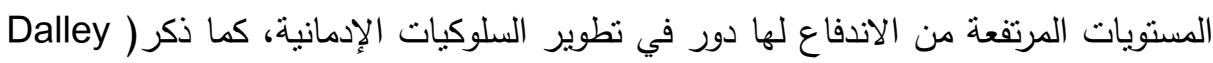
(et al, 2011,67) أن المدمن ينسم بالاندفاعية التي تؤدي إلى نطور استخدمة للمواد

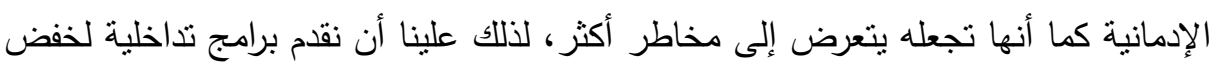

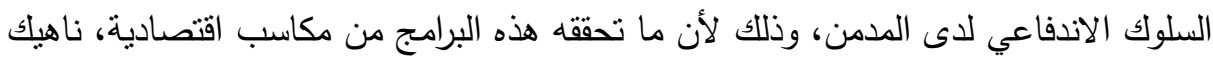

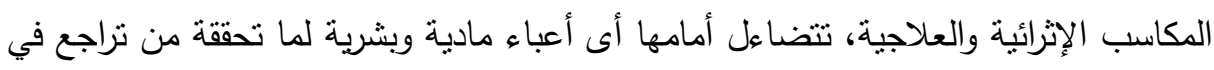
معدلات تعاطي المخدرات.

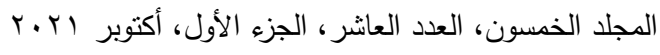

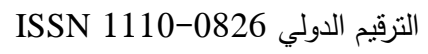

$$
\begin{aligned}
& \text { الترقيم الدولي الموحد الإلكتروني 3178-2636 }
\end{aligned}
$$




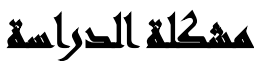

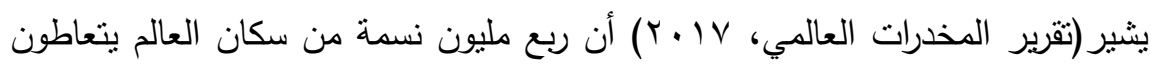

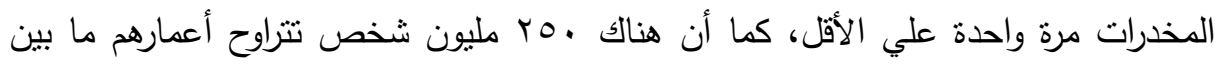

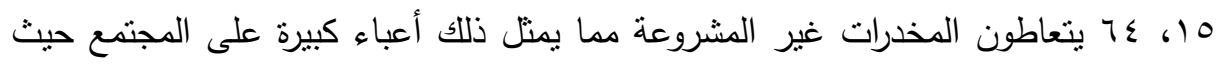

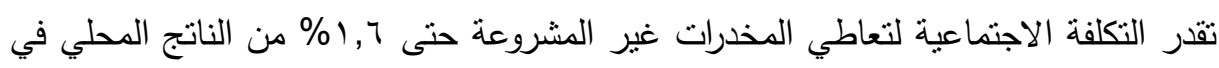

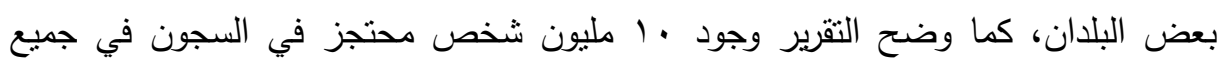

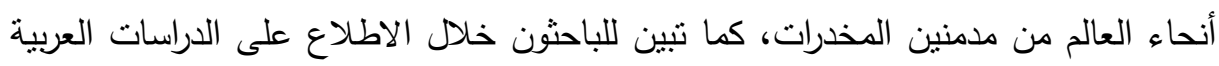

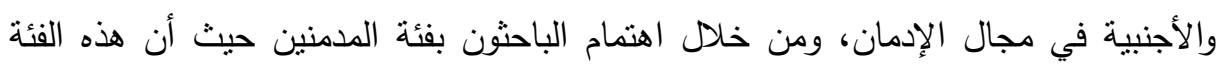

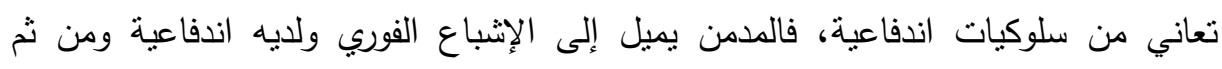

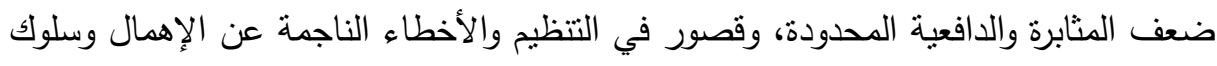

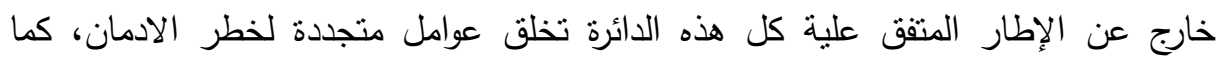

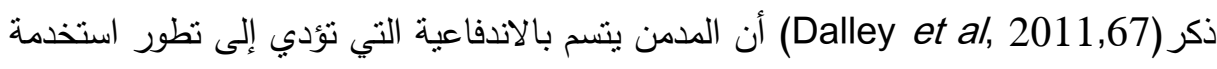
للكواد الإدمانية كما أنها تجعله ينعرض لدخاطر أكثر وقصور في التنظيم.

\section{أسئلا السوراسما}

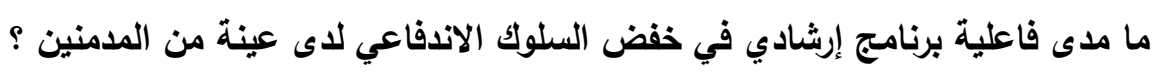
وينبثق من هذا التساؤل الرئيسي التساؤلات الفرعية الأتية:

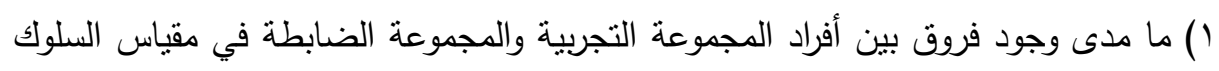

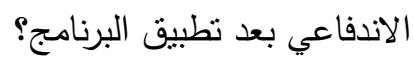

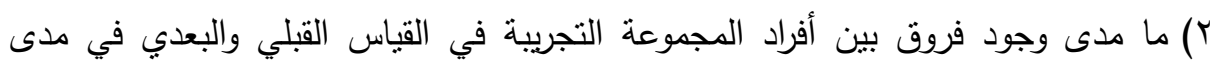

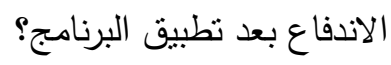

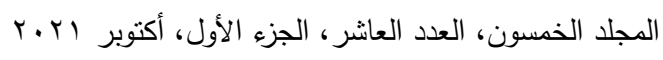

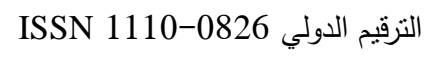

$$
\begin{aligned}
& \text { الترقيم الدولي الموحد الإلكتروني 3178-2636 }
\end{aligned}
$$


مجلة العلوم البيئية

كلية الدراسات العليا والبحوث البيئة - جامعة عين شمس البئة

ياسمين حمدي صادق وآخرون

r) ما مدى وجود فروق بين أفراد المجموعة التجريبية في السلوك الاندفاعي وذلك في القياس

البعدي والنتبعي ؟ مدود وجود

\section{أهمري التورسم}

\section{الأهمية النظرية}

( ) تكمن أهمية الدراسة الحالية في تقديم برنامج إرشادى لخفض السلوك الاندفاعى لدى عينة من المدمنين، وذللك يفيد باحثن آلخدن آخرون.

\section{الأهمية التطبيقية التبنة}

( ) إعداد برنامج لخفض السلوك الاندفاعي لدي المدمنين.

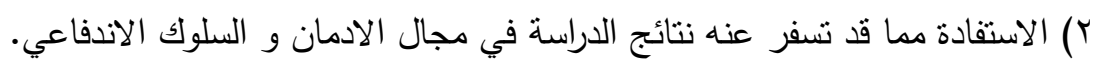

\section{أهماهيم الصورامة}

( ) خفض السلوك الاندفاعي لدى المدمنين.

\section{هروضر المهمث}

1 - توجد فروق بين متوسطي رتب درجات أفراد المجموعة التجربية والمجموعة الضابطة في

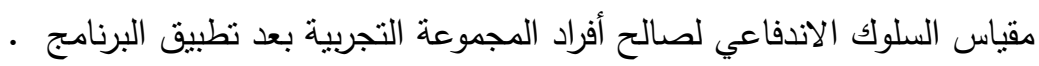

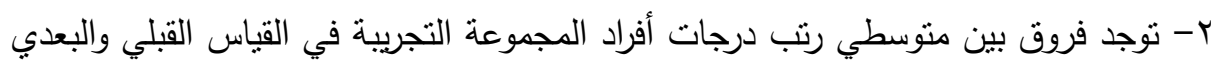

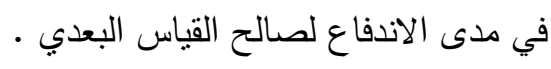

r- لا نوجد فروق بين متوسطي رتب درجات أفراد المجموعة التجريبية في السلوك الاندفاعي وذلك في القياس البعدي والتتبعي.

308

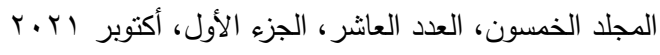

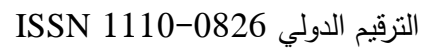

$$
\begin{aligned}
& \text { الترقيم الدولي الموحد الإلكتروني 3178-2636-2082 }
\end{aligned}
$$




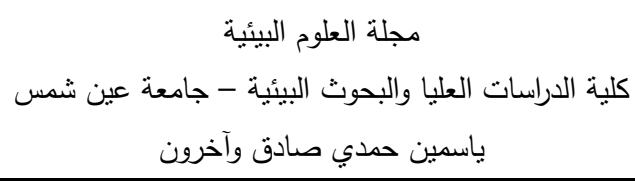

\section{هبوض الكواسمة}

أولاً: الحد البشري: العينة الاستطلاعية: تكونت من ·ب من المدمنين المماتلين لعينة الدراسة الاساسية. العينة الاساسية: تكونت من الاسبة، 17 امن مدمني الهيروين المنتكسين، تتراوح أعمارهم الزمنية. بين

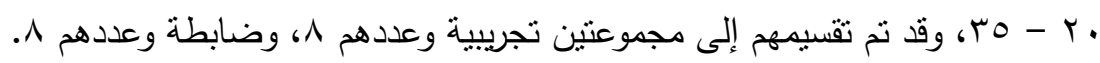

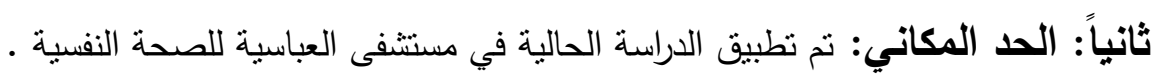

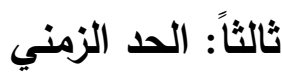

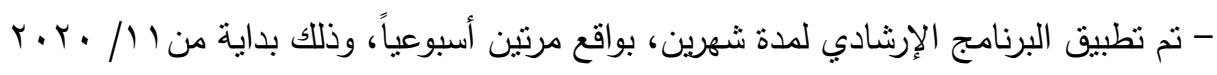

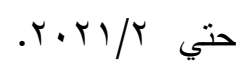

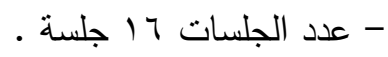

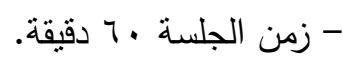

\section{منهمج القراسلا}

أستخدم الباحثون المنهج التجريبي في الدراسة الحالية باعتبارها تجربة هدفها الاساسي الاستي

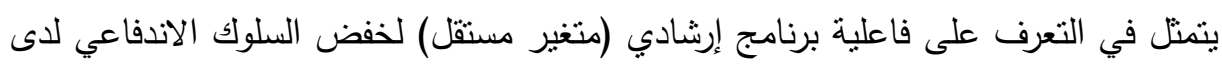
الدمنين (متغير نابع ).

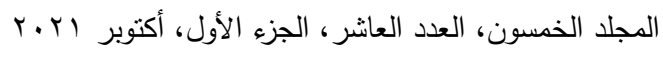

$$
\begin{aligned}
& \text { التزقيم الدولي 0826- ISSN 1110 } \\
& \text { الترقيم الدولي الموحد الإلكتروني 3178-2636-26 }
\end{aligned}
$$




\section{مجلة العلوم البيئية \\ كلية الدراسات العليا والبحوث البيئية - جامعة عين شمس لهن \\ ياسمين حمدي صادق وآخرون}

\section{همخاهيه الصراسمة}

السلوك الاندفاعي: تعرف الاندفاعية بأنها نقص القدرة على التحكم في الذات، أو نقص

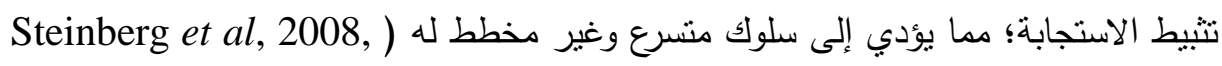

التعريف الإجرائي للاندفاعية: هو ضعف قدرة الفرد على التفكير الجيد والتخطيط في المواقف

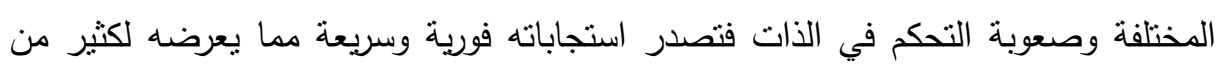
المشكلات.

الإدمان: هو فقدان القدرة على التحكم والسيطرة في استخدام مادة ما، مع قدرة الذات الإجبارية في استخدام المخدر بشكل منتظم، والانشغال القهري بالحصول على المادة المخدرة

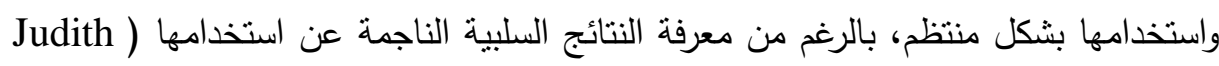
., and et al ,2001,1601 التعريف الإجرائي للإدمان: هو حالة تعلق شديده بالمخدر تؤدي إلى تدهور ملحوظ في سلوك

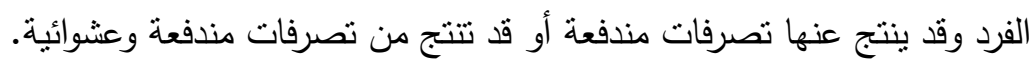

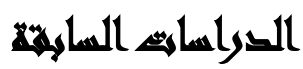

دراسات عن السلوك الاندفاعي والإدمان:

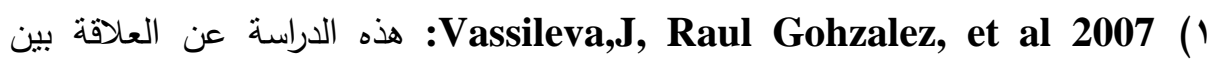
الإدمان و الاندفاع المعرفي والحركي، تهدف هذه الدراسة للتعرف على مدى تأثنر استخدام

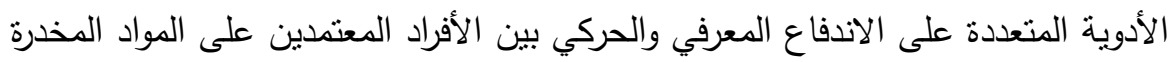
الذين استخدموا الكوكايين أو الهيروين في المقام الأول، وتكونت عينة الدراسة من الأن ل.

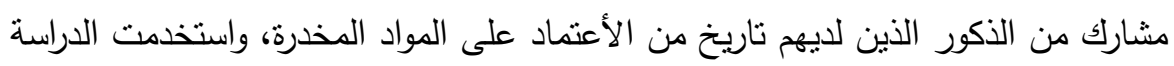
مقياس (الاستخدام المتعدد للأدوية ودرجة المعادة للمجتمع ) الذي تم تقيم الاعيمه باستخدام)

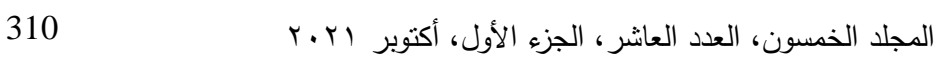

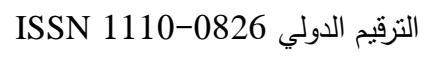

$$
\text { التزقيم الدولي الموحد الإلكتروني 3178-2636 التيم }
$$


مقياس التنشئة الاجتماعية / لجرد كاليفورنيا النفسي COI - SO مقياس الاندفاع

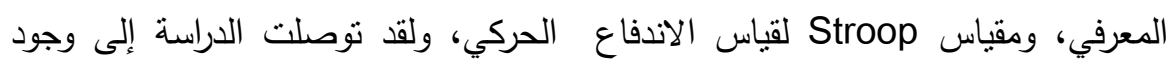
علاقة بين الإدمان والاندفاع الحركي العام، كما أظهرت الدراسة أن كلما انخفض الإنفاع الإدمان ظهر تحسن كبير في الاندفاعية و اتخاذ القرار.

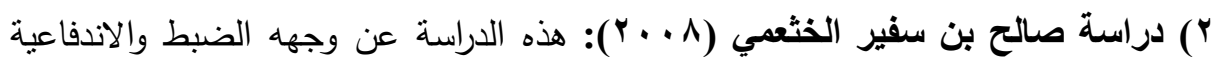

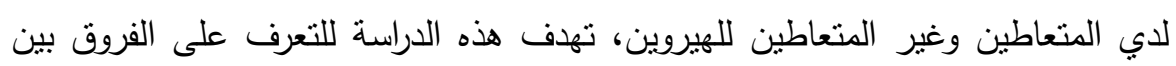

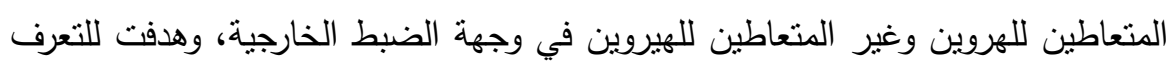
على الفروق بين المتعاطين للهيروين وغير المتعاطين في أسلوب الاندفاع والتروي، وهدفت للتعرف على الفروق بين المندفعين والمتروين في وجهة الضبط لدي العينة الكلية،

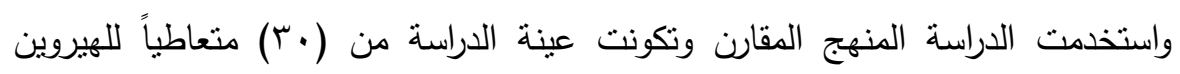

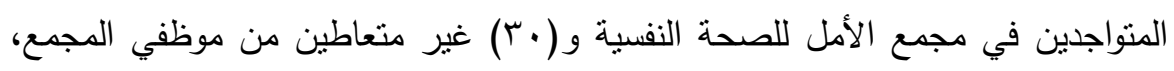
واستخدمت الدراسة مقياس وجهه الضبط لروتر، واختبار تزاوج الاشكال المألوفة لكاجان،

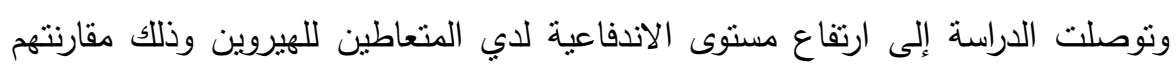
بغير المتعاطين للهيروين، كما توجد فروق بين المتعاطين للهيروين وغير المتعاطين في وجهة الضبط الخارجي لصالح المتعاطين للهيروين، كما توجد فروق بين المندفعين والمتروين في وجهة الضبط لدي العينة الكلية وعينة المتعاطين للهيروين وذلك لصالح المندفعين. ץ) دراسة Vassileva, J, Stefan Georgiev, et al, 2011 : هذه الدراسة عن مدمنين الهيروين السيكوباتيين وعلاقته بالاندفاع المعرفي العصبي، وتهدف هذه الدراسة للتحقق

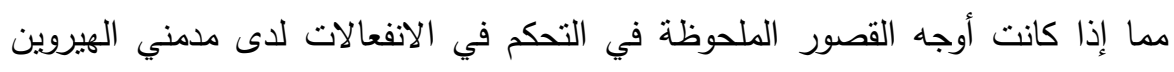

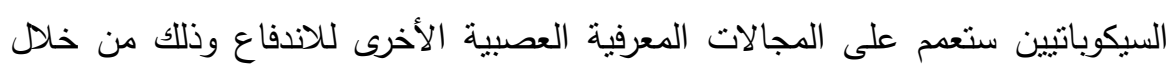

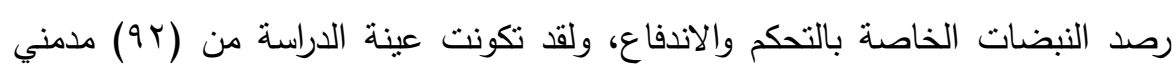

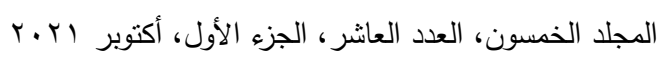

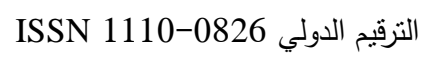

$$
\begin{aligned}
& \text { الترقيم الدولي الموحد الإلكتروني 3178-2636-26 }
\end{aligned}
$$




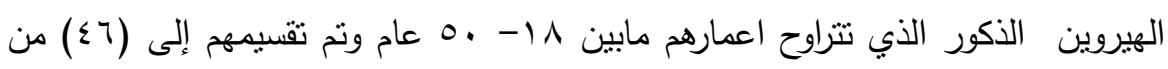

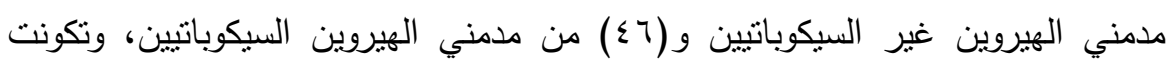

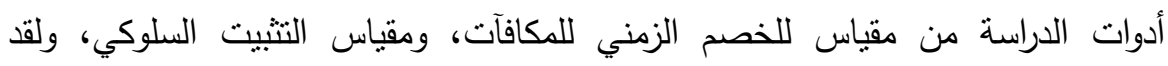
توصلت الدراسة أن مدمنين الهيروين السيكوباتيين يظهرون أندفاعاً أكثر عند اتخاذ

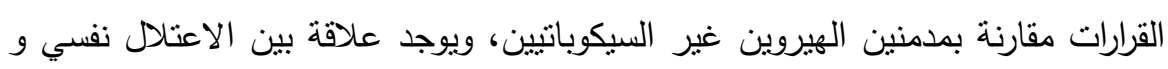
تفاقم حالات العجز في اتخاذ القرارات لدى مدمني الهيروين السيكوباتيين.

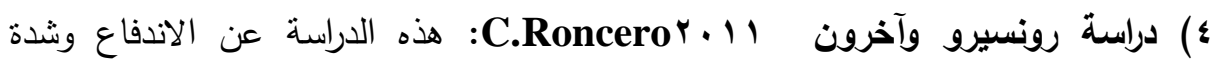
الإدمان في المرضى المعتمدين على الكوكايين والكوكايين والهيروين والهيروين، تهدف لهده الدراسة إل دراسة العلاقة بين الاندفاع وشدة الإدمان لدى ثلات مجموعات، ولقد تلكونت ولتين

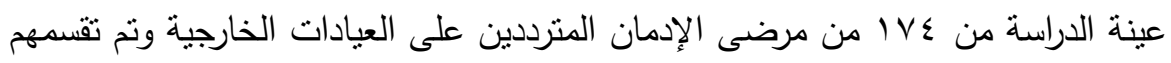

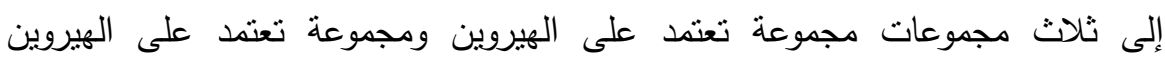

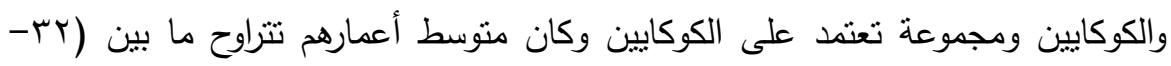
إ سنة) وكان rی1\% منهم من الرجال، ولقد استخدمة الدراسة مقياس (Barrat) للاندفاعية، واستخدمة المقابلة الموحدة شبة المنظمة (Europ Asi )، ولقد توصلت الدان الداسة أن مدمنون الهرويين يظهرون تحكماً أقل في الانفعالات مقارنة بغيرهم، و وجود فروق بين المجموعة المعتمدة على الكوكايين والمجموعة المعتمدة على الهيروين وذلك في لئي الاندفاع الحركي، و وجود اختلاف بين المجموعات فكانت في المجال الطبي المجموعة

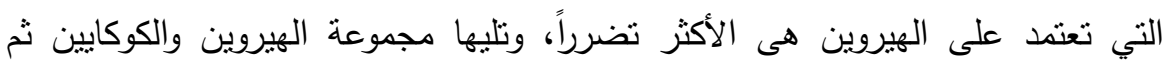
المجموعة التي تعتمد على الكوكايين. •) دراسة Esra Cicek, I, Ebrahim Eren, et al 2017 هذه الدراسة عن الاندفاع

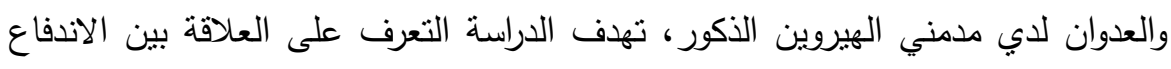

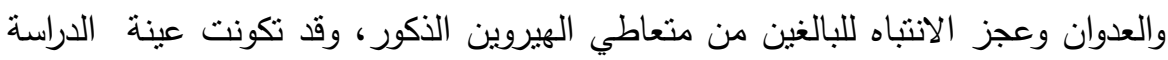

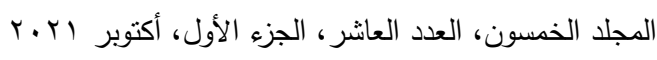

$$
\begin{aligned}
& \text { التزقيم الدولي 0826- ISSN 1110 } \\
& \text { الترقيم الدولي الموحد الإلكتروني 3178-2636-26 }
\end{aligned}
$$


على با فرداً من الذكور ونم تقسيم العينة إلى مجموعة مراقبة وتضم اب من الأفراد

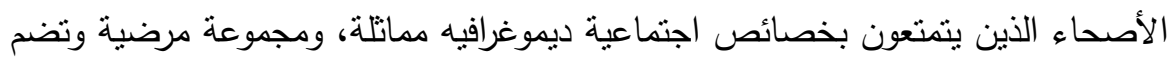
اب من المرضي مستخدمي الهيروين، واستخدمت الدراسة ( مقياس الاندفاع إعداد: Barratt لاضطراب فرط الحركة ونقص الانتباه (ADHD)، ولقد توصلت الدراسة إلى وجود درجات أعلى بكثير من الاندفاع والعدوان واضطراب فرط الحركه ونقص الانتباه لدي ونداه

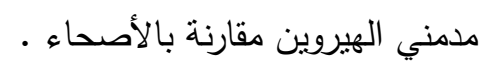

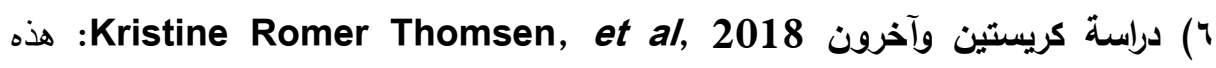
الدراسة عن الصفات الاندفاعية والسلوكيات المرتبطة بإدمان الثباب، تهدف هذه الدراسة

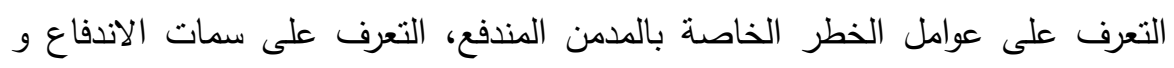
مؤشرات السلوكيات المتعددة المتعلقة بالإدمان والمخدرات، وتم اختيار المشاركين وكان

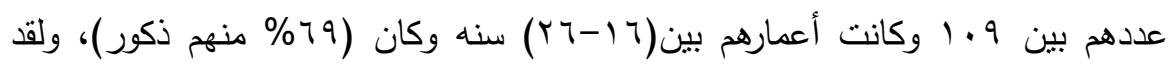
استخدمت الدراسة (استبيان upps-p) والاسنبيانات الموحده تقيم استخدام المواد المخدرة

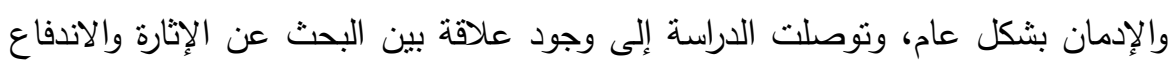
والإدمان، كما أظهرت الدراسة أن سمة الاندفاع مرتبطة بالسلوكيات المتعددة للمدمن.

\section{الأطار النظظرى للقواسة}

الاندفاعية: لقد ميز (Bechara, 2002, 1674) بين الاندفاعية السلوكية (الحركية)

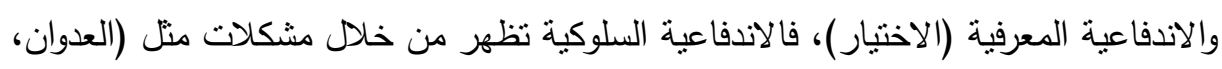

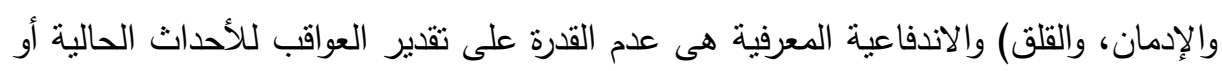

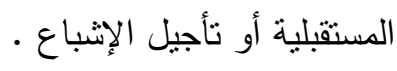

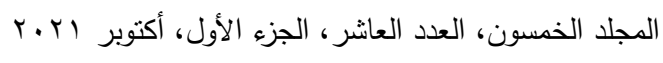

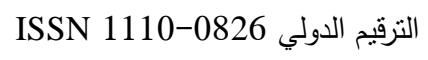

$$
\begin{aligned}
& \text { الترقيم الدولي الموحد الإلكتروني 3178-2636 }
\end{aligned}
$$


ولقد افترض العالم (Dickman, 1990) وجود نوعين من الاندفاعية، الأول الاندفاعية

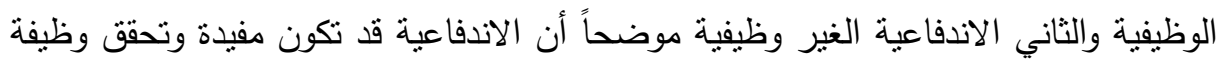
في ظروف معينة فقد يتطلب الأمر أنخاذ قرارات سريعة في بعض المواقف أو سرعة في

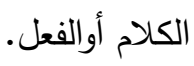
وبالرغم من أن السلوك الاندفاعي يعتبر سلوك غير وظيفي إلا أنه قد يكون له دور

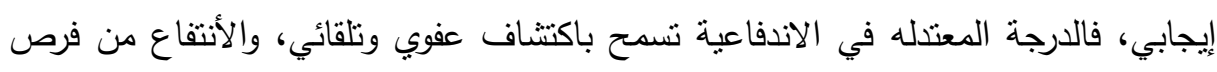

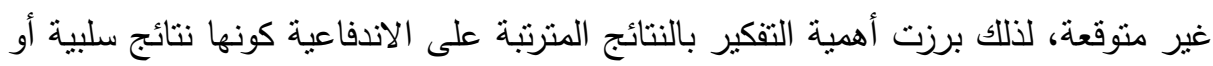

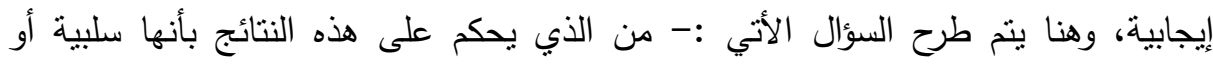

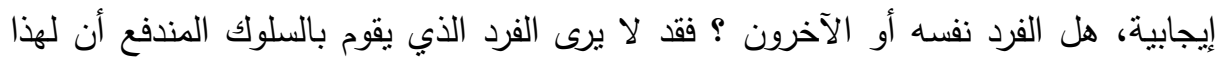

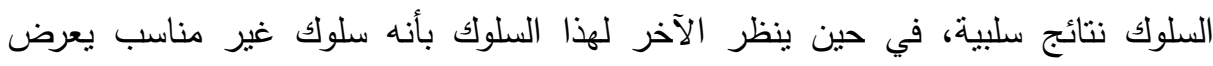

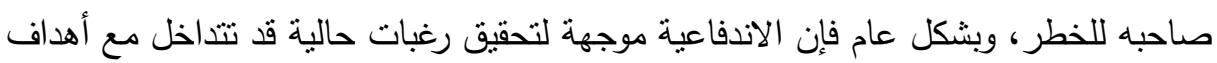
بعيدة الددى، والاندفاع خطر والاستجابة المنسرعة فيها ميل للخطأ وأثكال الاندفاع معظمها لا تولد الفوائد للمجتمع أو الفرد (Clark \& Grunstein, 2004, 50). تصنيفات الاندفاعية: يوضح حمدى الفرماي ( الاندفاعية \التروي) بأن الاندفاعية تعتبر طريقه الفرد المميزه في تتاول المعلومات سواء في استقبالها أو الإدلاء بها في التعامل المميز مع المواقف الإدراكية بصفة عامة ويقول أن الأفراد المترون هم الذين يرتكبون عدد أقل من الأخطاء ويتميزون ( بطء مع الدقة ) وأن الأفراد المندفعون يرتكبون عدداً من الأخطاء أكبر الإدرئ

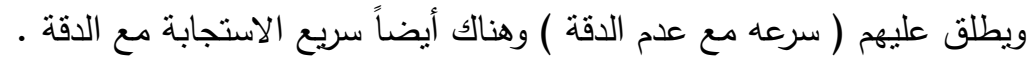

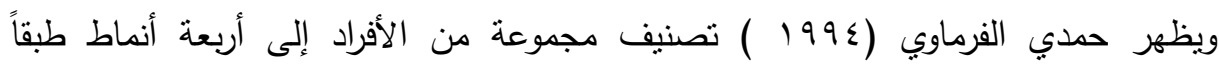

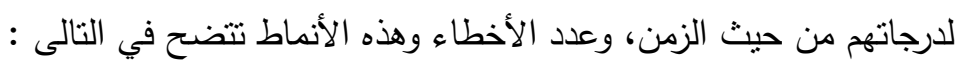

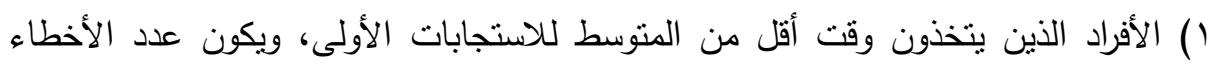


r) أفراد يتخذون وفتا أكبر من المتوسط في الاستجابات الأولى، ويرتكبون عدد أخطاء أقل من المتوسط، وينم تصنيف هؤلاء الأفراد على أنهم يتصفون بالتروي وذئ وذلك لأنهم أكثر

r) أفراد يأخذون وقتا أقل من المتوسط في الاستجابة الأولى، ويرتكبون عدد أخطاء أقل من

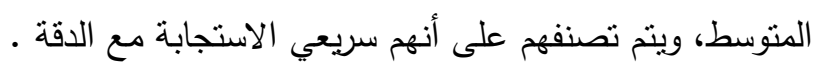

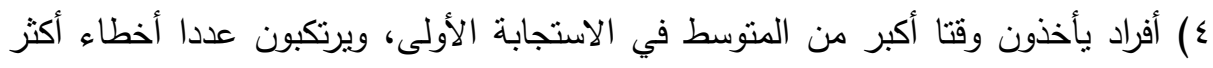

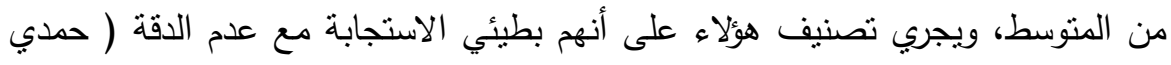

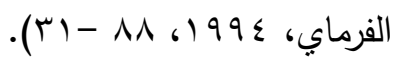

الإدمان: يعرفه جوديز وآخرون (Judith, et al, 2001, 160) بفقدان القدرة على التحكم والسيطرة في استخدام مادة ما، والانشغال القهري بالحصول على المادة المخدرة واستخدمها بشكل منتظم، بالرغم من معرفة النتائج السلبية الناجمة عن استخدمها.

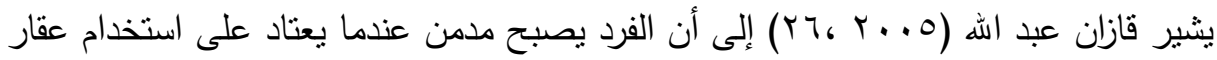

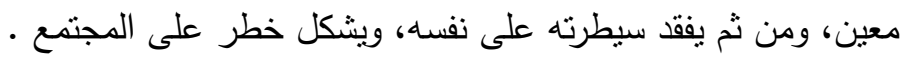

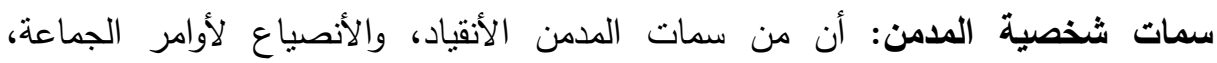

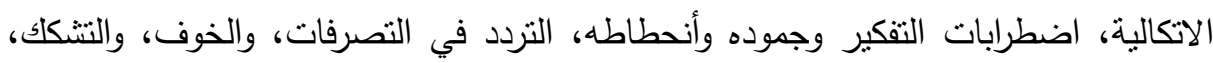

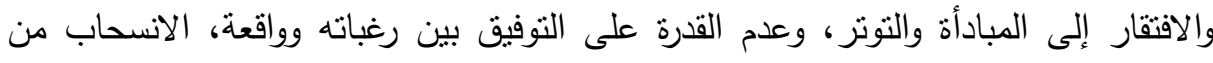

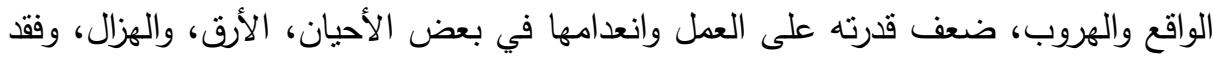

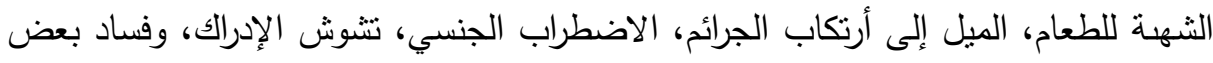

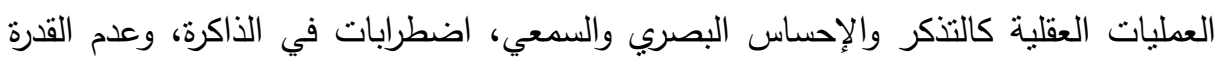
على إرجاء رغباته وغرائزه، والثعور بالعجز والنقص والدونية واستخدام الحيل الدفاعية لمدارة

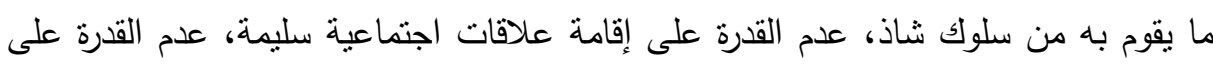

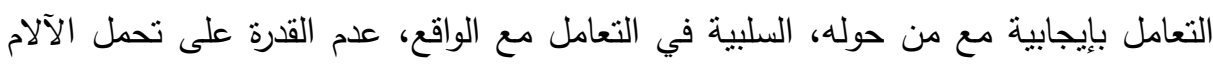

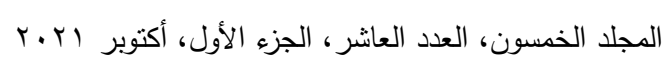

التزقيم الدولي 0826- ISSN 1110

$$
\text { الترقيم الدولي الموحد الإلكتروني 3178-2636 التروب }
$$




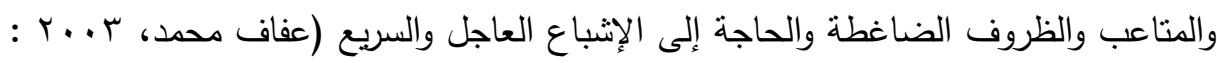
•)، كما يتسم المدمن بالاندفاعية كما ذكر محمد حسن غانم (

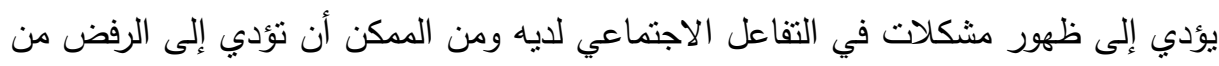

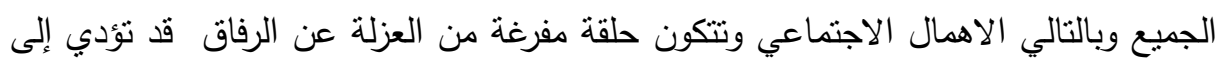

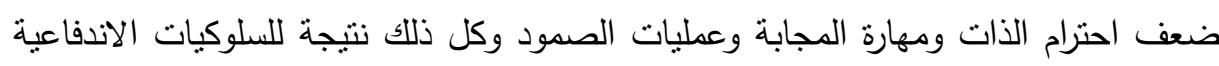
الغير ملائمة، كما أن سمات المدمن التي هى ضعف المثابنابرة والدافعية المحدودة وقصور التظظيم تخلق عوامل متجددة للخطر وتضيق معها فرصة الإتصاف بالصمود النفسي ـ (سام

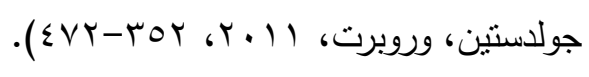

\section{الإجبراعايت المنهجية للتصواسمة}

\section{مجموعة الدراسة الإستطلاعية:}

العينة الاستطلاعية: تكونت من ·ـ من المدمنين المماتلين لعينة الدراسة الاساسية، وتم

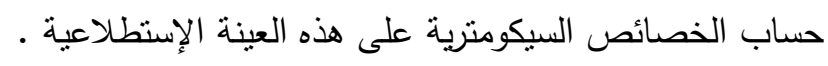
العينة الاساسية: تكونت من 7 امن مدمنين الهيروين المنتكسين الذكور، تتراوح أعمارهم

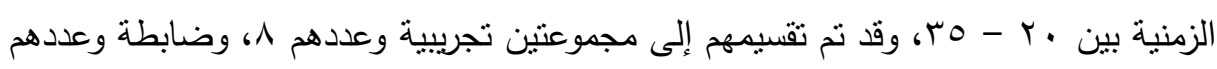

الأساليب الإحصائية: اختبار ويلكوكسون، اختبار مان ويتتى.

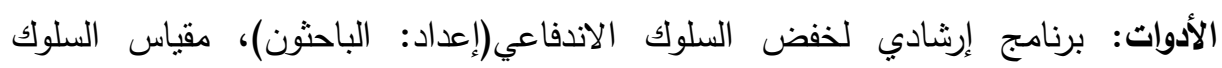
الاندفاعي (إعداد : الباحثون ).

أولاً: البرنامـج:

$$
\begin{aligned}
& \text { المجلد الخمسون، العدد العاشر، الجزء الأول، أكتوبر اYr.r } \\
& \text { الترقيم الدولي 0826-0 التئي } \\
& \text { الترقيم الدولي الموحد الإلكتروني 3178-2636 }
\end{aligned}
$$




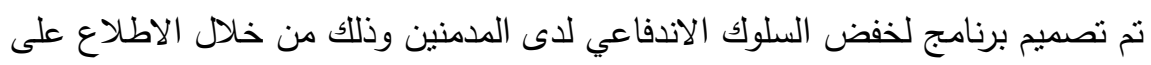
المراجع العلمية والدراسات المتخصصة، وقد أعتمد الباحثون فى تصميم البرنامج على النظرية المعرفية السلوكية. ويهدف البرنامج إلى (أن يتعرف المدمنين على السلوك الاندفاعي- أن يدرك المدمنين

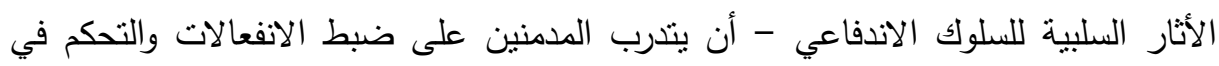
الذات- أن يمارس المدمنين الاسترخاء خاصة عند الانفعال - أن يقوم كل مدمن بتحديد

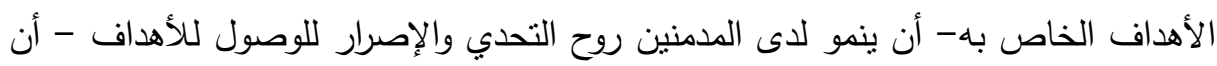

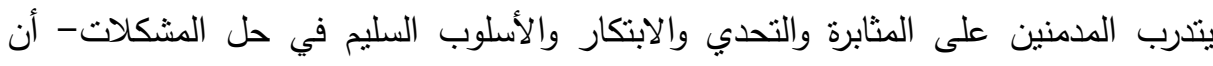
يرغب المدمنين في خفض السلوك الاندفاعي - أن يكون المدمنين نظرة إيجابية للذات - أن الن النين يرغب المدمنين في تحقيق الإسترخاء).

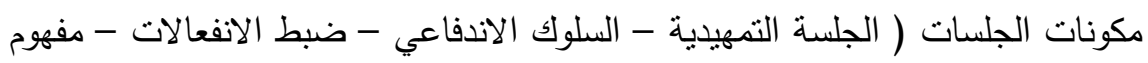
الذات - تحديد الأهداف - التفاؤل - العلاقات الاجتماعية - حل المشكلات واتخاذ القرار الصبر وتأجيل الإثباع- الجلسة الختامية) الفنيات المستخدمة في البرنامج: ( المحاضرة والمناقثة الجماعية - التعزيز - النمذجة الواجب المنزلي - تقيم الذات - لعب الدور - الإششاد الديني- التنفيس الانفعالي - إدارة الذات -التخيل - الاسترخاء- الحوار السقراطي). ثانياً: مقياس السلوك الاندفاعي: تعريف الاندفاعية : ضعف قدرة الفرد على التفكير الجيد والتخطيط في المواقف المختلفة وصعوبة التحكم في الذات فتصدر استجاباته فورية وسريعة مما يعرضه لكثثر من المشكلات

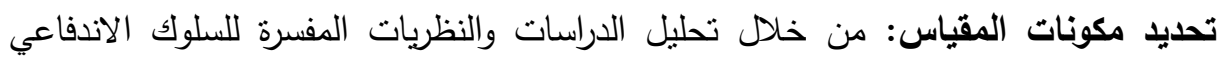
وكذلك المقاييس السابقة قد تم تصنيف المقياس إلى عدة مكونات أساسية وهى (ضعف القدرة على التفكير الجيد والتخطيط، ضعف القدرة على التحكم في الذات).

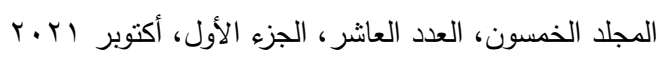

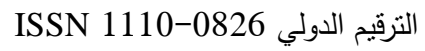
الترقيم الدولي الموحد الإلكتروني 3178-2636-26 
- ضعف القدرة على التفكير الجيد و التخطيط: هو ضعف القدرة على وضع الخطط المستقبلية المناسبة قبل إتخاذ القرارات، والتقكير الجيد في المواقف المختلفة .

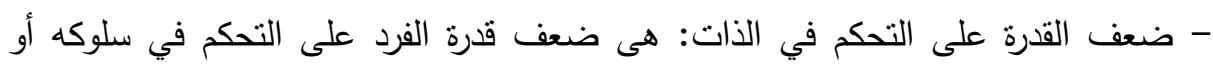

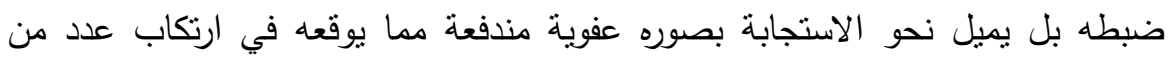

$$
\text { الأخطاء والمشكلات السلوكية. }
$$

وصف المقياس: يتكون مقياس السلوك الاندفاعي من (•r) عبارة، موزعة على مكونين

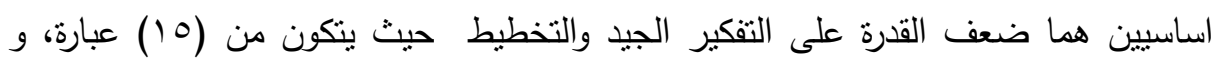
ضعف القدرة على التحكم في الذات حيث يتكون من (10) عبارة . الثبات والصدق لمقياس السلوك الاندفاعي : • صدق المحكمين: لقد تم عرض المقياس على مجموعة من أساتذة علم النفس، للتأكد من صلاحية المقياس، ومناسبة عباراته، وتم الأخذ بما اقترحة المحكمين.

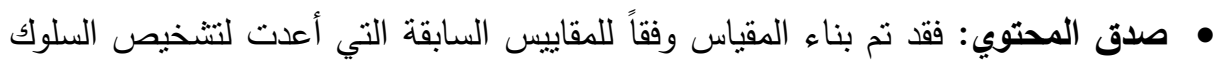
الاندفاعي والمفاهم المنداخلة معه، وكذلك وفقاً للأطر النظرية والكتابات السيكولوجية

$$
\text { لسمات ومظاهر السلوك الاندفاعي. }
$$

\begin{tabular}{|c|c|c|}
\hline معامل ألفا & عدد العبارات & آبعاد المقياس \\
\hline$\cdot, \wedge 07$ & 10 & المكون الاول: ضعف القدرة على التفكير والتخطيط الجيد \\
\hline$\cdot, \wedge 79$ & 10 & المكون الثاني: ضعف القدرة على التحكم في الذات \\
\hline$\cdot, 9 Y 7$ & r. & إجمالي مقياس السلوك الاندفاعي \\
\hline
\end{tabular}

• • ثبات المقياس: الثبات بإستخدام معادلة ألفا كرونباخ (Alpha Cronbach):

من التحليل السابق لثبات عبارات المقياس نجد أن قيم ألفا قيمة جيدة أكبر من (0, •) بلغت (107,، •، 179, •) لكل من (المكون الاول: ضعف القدرة على التفكير والتخطبط الجيد، المكون الثاني: ضعف القدرة على التحكم في الذات)، وكانت قيمة ألفا لإجمالى

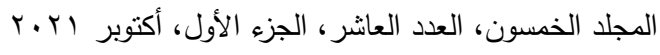

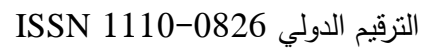

$$
\begin{aligned}
& \text { التزقيم الدولي الموحد الإلكتروني 3178-2636-2082 }
\end{aligned}
$$




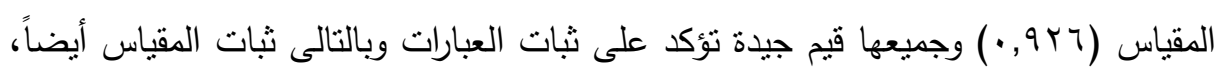
لذا كان من الممكن الاعتماد عليه في التطبيق.

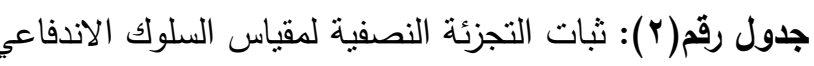

\begin{tabular}{|c|c|c|}
\hline معامل الارتباط بين الجزيين & معامل الارتباط & المتغيرات \\
\hline$\cdot, 9 \%$. & $\cdot, 107$ & الجزء الأول \\
\hline
\end{tabular}

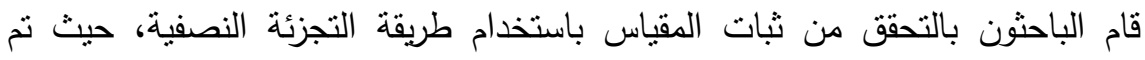

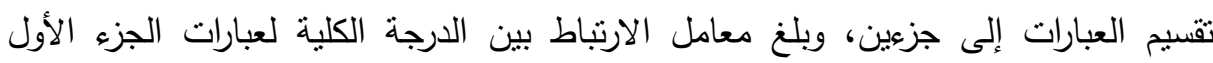
والدرجة الكلية للمقياس وهي (000,·)، وحُسب معامل الارتباط بين الدرجة الكلية لعبارات

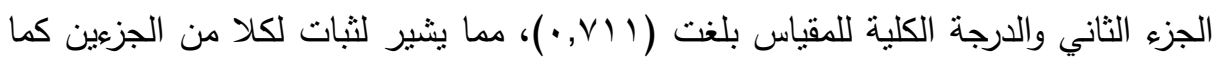

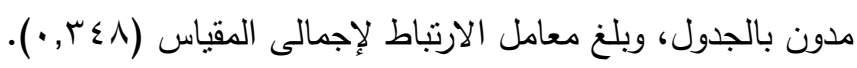

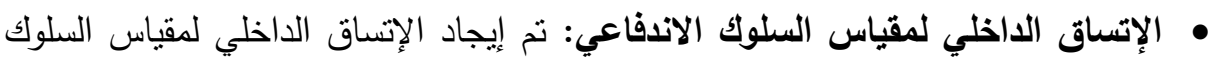

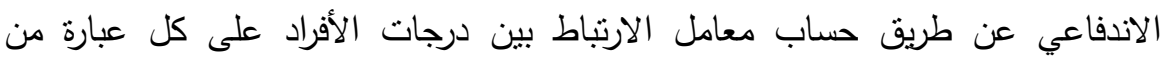
عبارات الدقياس والدرجة الكلية للبعد الذي تنتمي إليه.

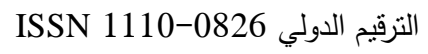
التزقيم الدولي الموحد الإلكتروني 3178-2636 
مجلة العلوم البيئية

كلية الدراسات العليا والبحوث البيئية - جامعة عين شمس لئئ

ياسمين حمدي صادق وآخرون

جدول(r): الإتساق الداخلي لعبارات مقياس السلوك الاندفاعي

\begin{tabular}{|c|c|c|c|c|c|}
\hline معامل الارتباط & رقم العبارة & البعد & معامل الارتباط & رقم العبارة & البعد \\
\hline$* *, \vee \vee T V$ & 1 & \multirow{15}{*}{ 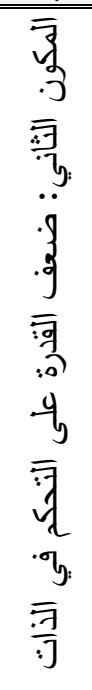 } & "***, フイ & 1 & \multirow{3}{*}{$\begin{array}{l}\overline{3} \\
\overline{3} \\
\bar{x}\end{array}$} \\
\hline${ }^{*} *,, V \vee Y$ & r & & $* *, \vee \vee \wedge \varepsilon$ & $\bar{r}$ & \\
\hline ***, オY & $r$ & & $* *, \wedge \ldots$ & $r$ & \\
\hline 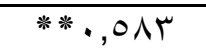 & $\xi$ & & ***, . & $\varepsilon$ & 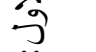 \\
\hline$* *, 07 \wedge$ & 0 & & $* *, O V T$ & 0 & $\ddot{q}$ \\
\hline$* *, 70 \leq$ & 7 & & $* *,, \Sigma \wedge \varepsilon$ & 7 & 1 \\
\hline **, & $\mathrm{V}$ & & **, & $\bar{V}$ & 可 \\
\hline **., & $\Lambda$ & & ***, ๖ §०ᄉ & $\Lambda$ & 7 \\
\hline **, OY. & 9 & & **,rT. & 9 & -4 \\
\hline$* *,, V \leq \Gamma$ & 1. & & $* *, 0 \wedge \mathrm{T}$ & 1. & \\
\hline 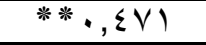 & 11 & & ***, & 11 & 词. \\
\hline **., Tr & Ir & & ***,0 $07 \varepsilon$ & IT & fi \\
\hline$* *, 0 \leq r$ & $1 \pi$ & & ** $\cdot, \varepsilon \wedge \varepsilon$ & $1 \pi$ & 可 \\
\hline **., OVI & $1 \varepsilon$ & & **., OrV & $1 \varepsilon$ & . \\
\hline ** $\cdot, \varepsilon \leqslant \leqslant$ & 10 & & $* *, 0 \leqslant \leqslant$ & 10 & - \\
\hline
\end{tabular}

يتضح من الجدول السابق أن جميع قيم معاملات الارتباط ذات دلالة إحصائية عند مستوى (1 +. +) لعبارات مقياس السلوك الاندفاعي، مما يؤكد على الإتساق الداخلي لعبارات المقياس.

وقام الباحثون بإيجاد معامل الارتباط بين الدرجة الكلية للبعد والدرجة الكلية للمقياس

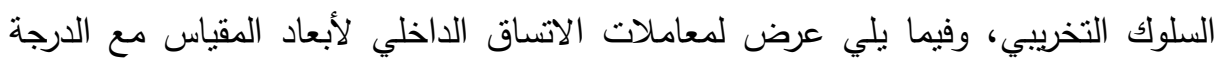

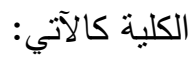

التزقيم الدولي 0826- ISSN 1110

الترقيم الدولي الموحد الإلكتروني 3178-2636 
جدول رقم(؛): الإتساق الداخلي لأبعاد مقياس السلوك الاندفاعي مع الدرجة الكلية للمقياس

\begin{tabular}{|c|c|c|}
\hline \multicolumn{2}{|c|}{ الارجة الكلية لمقياس السلوك الاندفاعى } & \multirow{2}{*}{ المتغيرات } \\
\hline الدالالة المعنوية & معامل ارتباط بيرسون & \\
\hline$\cdot, \cdots$ & r,974 & المكون الاول: ضنعف القدرة على التفكير \\
\hline$\cdot, \ldots 1$ & $\cdot, 971$ & المكون الثاني: ضعف القدرة على التحكم في \\
\hline
\end{tabular}

يوضح الجدول السابق الإتساق الداخلي لـقياس السلوك الاندفاعي وجد أن قيم معامل

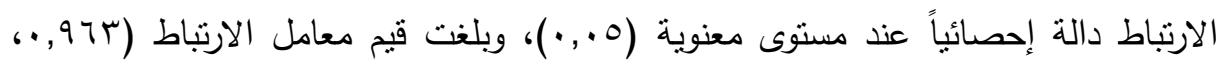
(79, • ·) لكل من (المكون الاول: ضعف القدرة على التفكير والتخطيط الجيد، المكون الثاني: ضعف القدرة على التحكم في الذات) على التوالى وهي قيم تؤكد على الإتساق الداخلي للمقياس.

\section{• صدق المقارنة الطرفية:}

جدول(ه): اختبار مان ويتتي لتوضيح الفروق الإحصائية بين درجات مقياس السلوك

\begin{tabular}{|c|c|c|c|c|c|c|}
\hline \multirow[b]{2}{*}{ المعنوية } & \multirow[b]{2}{*}{ قيمة Z } & \multicolumn{2}{|c|}{ الإرياع الأعلى } & \multicolumn{2}{|c|}{ الإرياع الأدنى } & \multirow[b]{2}{*}{ المتغيرات } \\
\hline & & مجموع & متوسط & مجموع & متوسط & \\
\hline (1) & $\begin{array}{l}- \\
, T V R \\
\end{array}$ & $99, \ldots$ & $M, \ldots$ & $r v, \ldots$ & $\varepsilon, 7 T$ & المكلى التفكير والاول: ضطيط القيدة \\
\hline 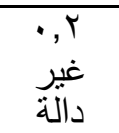 & D & $\Lambda \cdot, 0$ & $1 \cdot, \cdot 7$ & 00,0 & $7,9 \leq$ & المكون التانى في ضعف الذات القدرة \\
\hline 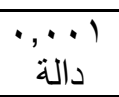 & $\begin{array}{c}- \\
r, V 09\end{array}$ & $9 \leq, \ldots$ & 11,10 & $\varepsilon r, \cdots$ & $0, r_{0}$ & إجمالى مقياس السلوك \\
\hline
\end{tabular}

تبين من الجدول السابق للفروق الإحصائية بين درجات مقياس السلوك الاندفاعي وجود فروق ذات دلالة إحصائية بين درجات الإرباع الأعلى والأدنى لكل من (المكون الاول:

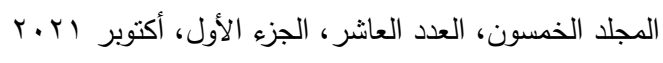

$$
\begin{aligned}
& \text { التزقيم الدولي 0826- ISSN 1110 } \\
& \text { الترقيم الدولي الموحد الإلكتروني 3178-2636 }
\end{aligned}
$$




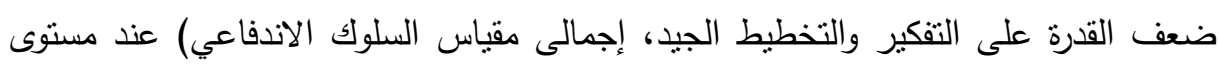
(0 . . •) حيث كانت قيم (Z) المحسوبة ذات دلالة إحصائية مما يؤكد على صدق المقياس. • تطبيق المقياس: تم تطبيق المقياس علي المدمنين في مسنتفى العباسية للصحة النفسية، دانه

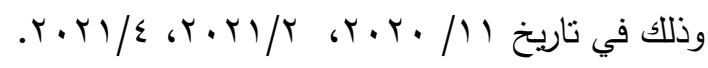

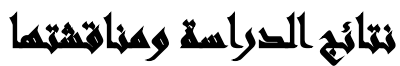

الفرض الأول: توجد فروف بين منوسطي رثب أفراد المجموعة التجريبية والمجموعة الضابطة في مقياس السلوك الاندفاعي لصالح أفراد المجموعة التجريبية بعد تطبيق البرنامج. جدول(†): اختبار (مان ويتتي) لحساب الفروق بين متوسطي رتب أفراد المجموعة التجريبية والمجموعة الضابطة في مقياس السلوك الاندفاعي لصالح أفراد المجموعة لئن

\begin{tabular}{|c|c|c|c|c|c|c|}
\hline \multirow[b]{2}{*}{ مستوية } & \multirow[b]{2}{*}{ "Z" قيمة } & \multicolumn{2}{|c|}{ التجريبية (ن = (^) } & \multicolumn{2}{|c|}{ الضابطة (ن= ^ ( ) } & \multirow{2}{*}{ المتغيرات } \\
\hline & & مجموع & متوبط & مجموع & متوبط & \\
\hline (1) & ץ,乞\1- & $r q, \cdots$ & $\varepsilon, 0$ & $1 \cdots, \cdot$ & Ir,o. & المكون الاول: ضفعف والتخطبط الجدرة على \\
\hline ( & r,rVr- & r., & $\varepsilon, 0$. & $1 \cdots$, & $1, r, 0$. & المكون التانىي: ضيع الذات القدرة على \\
\hline ( & r,rVr- & rq, . & $\varepsilon, 0$ & $1 \cdots$, & $1 Y, 0$. & إجمالى مقياس السلوك الاندفاعي \\
\hline
\end{tabular}

يتضح من الجدول السابق لحساب الفروق بين متوسطي رتب أفراد المجموعة التجريبية والمجموعة الضابطة في مقياس السلوك الاندفاعي بعد نطبيق البرنامج الآتي:

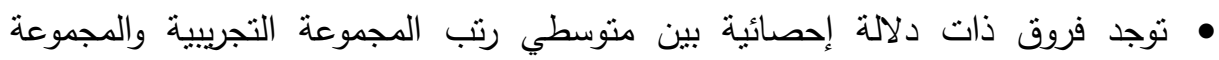

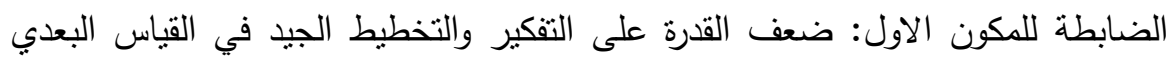

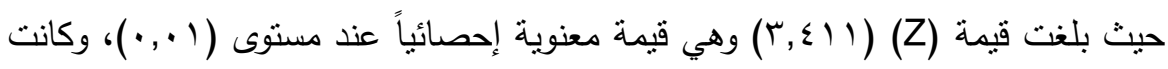

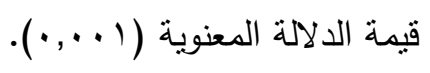

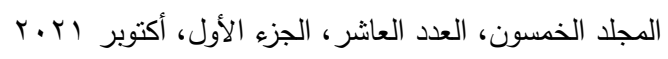

الترقيم الدولي 0826-08SN 1110

$$
\text { الترقيم الدولي الموحد الإلكتروني 3178-2636 }
$$


• توجد فروق ذات دلالة إحصائية بين متوسطي رتب المجموعة التجريبية والمجموعة

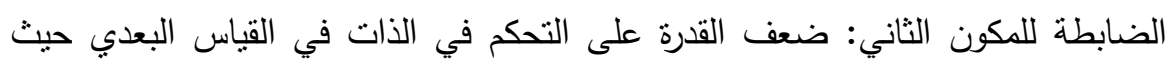

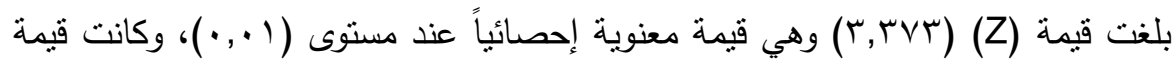

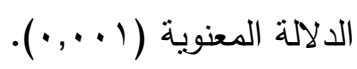

• توجد فروق ذات دلالة إحصائية بين متوسطي رتب المجموعة التجريبية والمجموعة

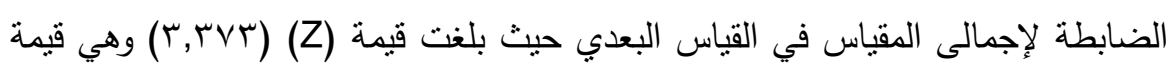

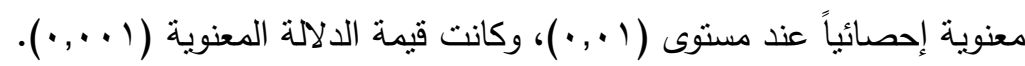

مناقشة نتائج الفرض الأول: مما سبق ثبت صحة الفرض الأول: نوجد فروق بين متوسطي رتب أفراد المجموعة التجريبية والمجموعة الضابطة في مقياس السلوك الاندفاعي لئي لصالح أفراد المجموعة التجريبية بعد نطبيق البرنامج، وذللك قد يكون نتيجة لإستخدام النظرية

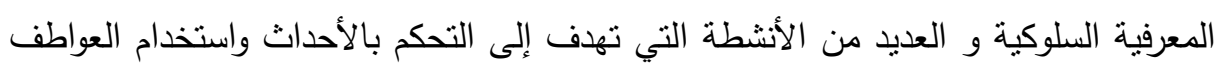

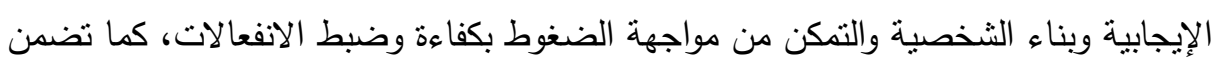

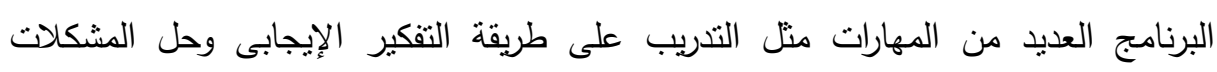
والمناقثنة والحوار والتتفيس الانفعالي، التخيل، كل هذا قد يحدث تنغير في مستوى السلوك

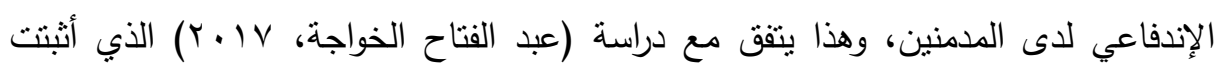

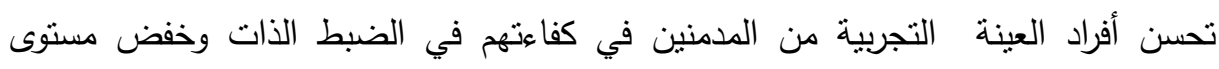
السيطرة والانشغال الذائد والثعور بالهفة مقارنتهم بالمجموعة الضابطة الهنة

التزقيم الدولي 0826- ISSN 1110 الترقيم الدولي الموحد الإلكتروني 3178-2636 
الفرض الثاني: توجد فروق بين متوسطي رتب أفراد المجموعة التجريبية في القياس القبلي

$$
\text { والبعدي في السلوك الاندفاعي لصالح القياس البعدي. }
$$

جدول (V): اختبار (ويلككسون) لحساب الفروق بين متوسطي رتب أفراد المجموعة التجريبية

\begin{tabular}{|c|c|c|c|c|c|c|}
\hline \multicolumn{7}{|c|}{ في القياس القبلي والبعدي في السلوك الاندفاعي } \\
\hline \multirow[b]{2}{*}{ الدالائةي } & \multirow[b]{2}{*}{ 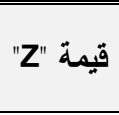 } & \multicolumn{2}{|c|}{ الرتب الموجبة } & \multicolumn{2}{|c|}{ الرتب السالبة } & \multirow[b]{2}{*}{ المتغيرات القياس } \\
\hline & & مجموع & متوسط & مجنبوع & متوسط & \\
\hline 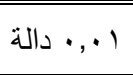 & r,OY૫- & $\cdot, \cdot \cdot$ & $\cdot, \cdot$ & $r 4, \cdots$ & $\varepsilon, 0$. & المكون الاول: ضنكير والتخطيط الجيدرة على \\
\hline 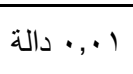 & $r, O Y \Sigma-$ & $\cdot, \cdot$ & •, & ז & $\varepsilon, 0$. & المكون الثانىي: ضعى الذات القدرة على \\
\hline 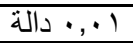 & $r, O Y \Sigma-$ & $\cdot, \cdots$ & $\cdot, \cdot$ & $r 4, \ldots$ & $\varepsilon, 0$. & إجمالى مقياس السلوك الاندفاعي \\
\hline
\end{tabular}

يتضح من الجدول السابق لحساب الفروق بين متوسطي رثب أفراد المجموعة التجريبية في القياس القبلي والبعدي في السلوك الاندفاعي الآتي: • توجد فروق ذات دلالة إحصائية بين متوسطي رتب التطبيق القبلي والتطبيق البعدي التباتي

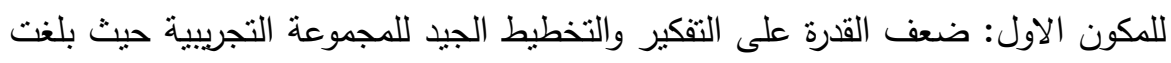

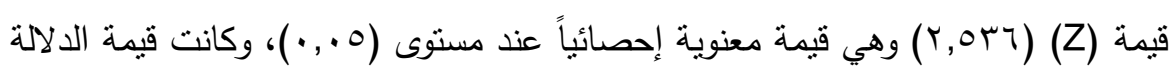

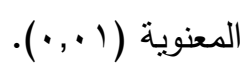

• توجد فروق ذات دلالة إحصائية بين منوسطي رتب التطبيق القبلي والتطبيق البعدي

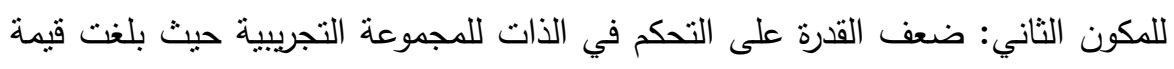

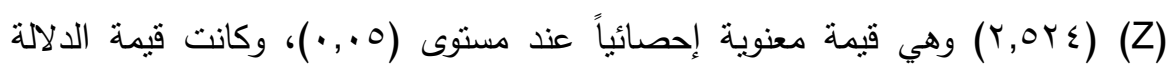

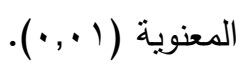

• توجد فروق ذات دلالة إحصائية بين متوسطي رتب التطبيق القبلي والتطبيق البعدي )

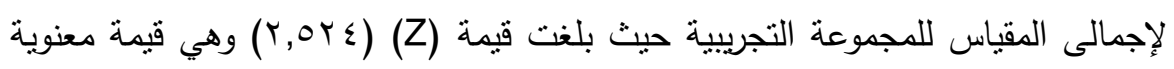

إحصائياً عند مستوى (0. . •)، وكانت قيمة الدلالة المعنوية (1 (. •).

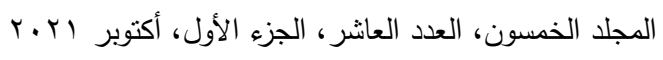

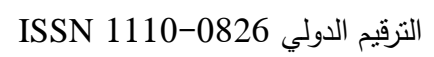

$$
\begin{aligned}
& \text { التزقيم الدولي الموحد الإككتروني 3178-2636 الني }
\end{aligned}
$$


مناقشة نتائج الفرض الثاني: مما سبق ثبت صحة الفرض الثاني: نوجد فروق بين متوسطي رتب أفراد المجموعة التجريبية في القياس القبلي والبعدي في السلوك الاندفاعي لئي لصالح القياس البعدي، قد يرجع ذلك إلي الاستراتيجيات التي أستخدمت في البرنامج منل فئل فئل فئل تمارين الاسترخاء والتتفس والتخيل، والتي بدورها ساعدت المدمنين علي التفاعلات التبادلية

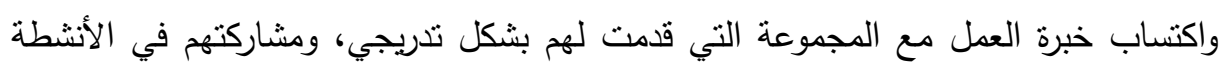

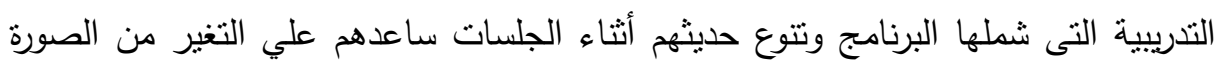

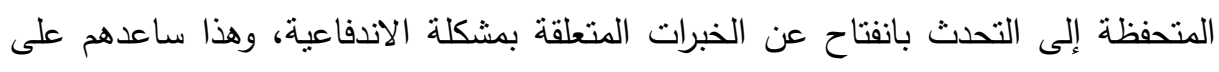

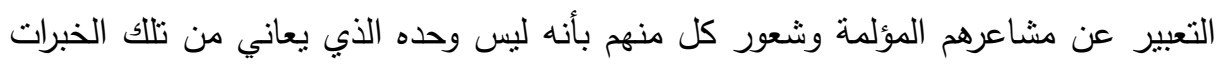

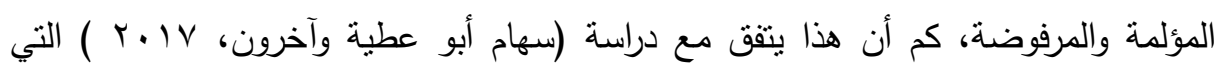

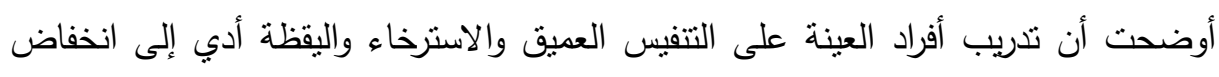
الاندفاعية لدى أفراد العينة التجربية بين القياس القبلي والبعدي، ولا تتعارض النتائج النئي السابقة

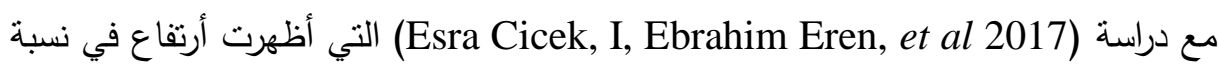
الاندفاع لدى مدمني الهيروين. الفرض الثالث: لا توجد فروق بين متوسطي رثب أفراد المجموعة التجريبية في السلوك الاندفاعي وذلك في القياس البعدي والتنبعي.

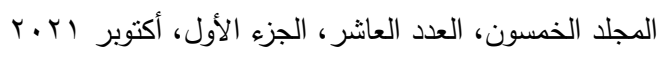

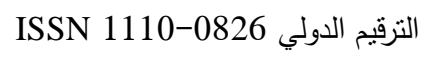

$$
\begin{aligned}
& \text { الترقيم الدولي الموحد الإلكتروني 3178-2636 }
\end{aligned}
$$


جدول(^): اختبار (ويلككسون) لحساب الفروق بين متوسطي رثب أفراد المجموعة التجريبية في

\begin{tabular}{|c|c|c|c|c|c|c|}
\hline & & \multicolumn{5}{|c|}{ السلوك الاندفاعي وذلك في القياس البعدي والتتبعي } \\
\hline الدالائي & قيمة" & موجموع & متوبسطب & مجتبوع & متوبِّن الرتب & إن آس \\
\hline غير 'ُّالة & $\overline{1, V T r}$ & 7 & Y & $\cdot, \cdots$ & $\cdot, \cdot$ & على المكنفير الاول: ضلتخطيط القيدرة \\
\hline 9","'الة:غير & $\cdot ., 10$ & $1 \varepsilon, 0$ & $\varepsilon, \wedge \Gamma$ & $1 \pi, 0$ & $\Gamma, \Gamma \wedge$ & 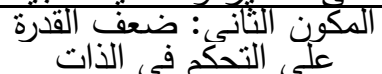 \\
\hline ', ', غلةير & $\overline{r_{q 1}}$ & $19, \ldots$ & $\varepsilon, \vee 0$ & $9, \cdots$ & $r, \cdots$ & عي السلوك \\
\hline
\end{tabular}

يتضح من الجدول السابق لحساب الفروق بين متوسطي رثب أفراد المجموعة التجريبية في السلوك الاندفاعي وذلك في القياس البعدي والتتبعي عدم وجود فروق ذات دلالة إحصائية

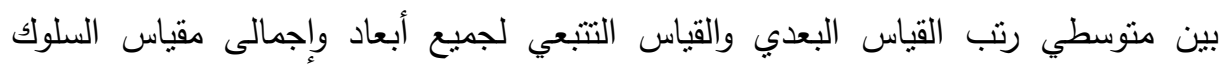
الاندفاعي حيث كانت قيم (Z) غير معنوية إحصائياً عند مسنوى (0. •. •). مناقشة نتائج الفرض الثالث: مما سبق ثبت صحة الفرض الثالث: لا توجد فروق بين منوسطي رتب أفراد المجموعة التجريبية في السلوك الاندفاعي وذلك في القياس البعدي

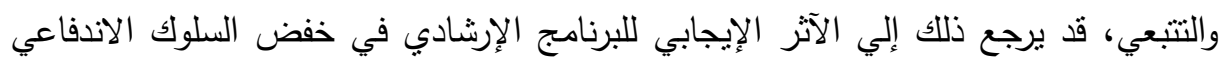

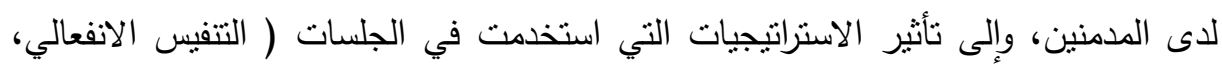

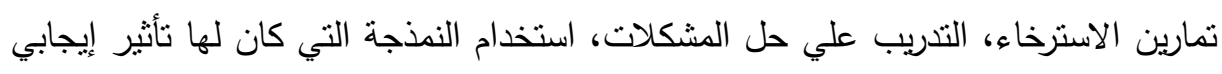

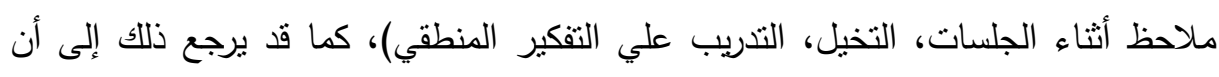

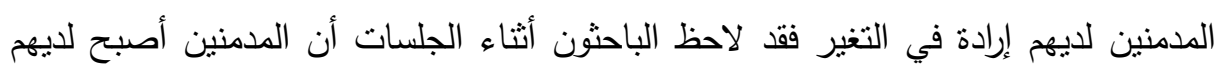

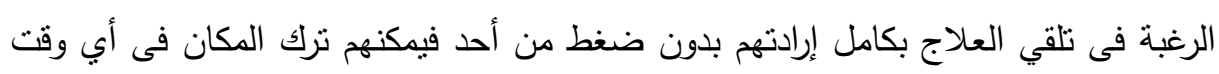

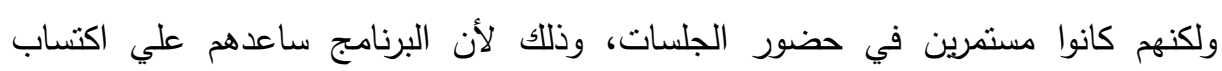

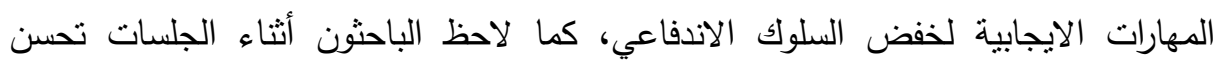

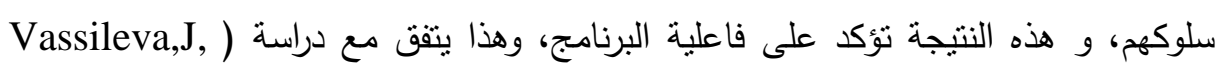
326

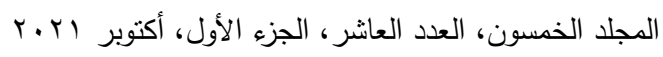

$$
\begin{aligned}
& \text { التزقيم الدولي 0826- ISSN 1110 } \\
& \text { الترقيم الدولي الموحد الإلكتروني 3178-2636-26 }
\end{aligned}
$$


Raul Gohzalez, et al 2007 التي أظهرت أن كلما انخفض الإدمان ظهر تحسن كبير في الاندفاعية، ولا يختلف مع دراسة (Esra Cicek, I, Ebrahim Eren, et al 2017) التي أظهرت أرتفاع في نسبة الاندفاع لدى مدمني الهيروين.

\section{اللمهيامت}

ا-تشجيع المتعافين من الإدمان على تعليم مهارات اجتماعية وذاتية ومعرفيه جديدة تساعدهم على مواجهة الصعاب والأحداث المتغيرة والتحولات المفاجئة التي تهدد أمنهم النفسي

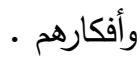

ץ-الاهتمام بإجراء دراسات تتضمن تعديل السلوك الاندفاعى لدى المدمنين وخاصة فئة الثباب وذلك لندرة هذه الدراسات .

r-تصميم برامج وقائية من قبل الهيئات الحكومية والمنظمات والمراكز المتخصصة في كيفية

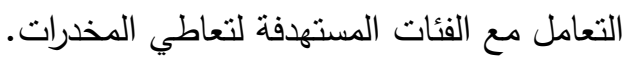
ع-نشر الثقافات النفسية المناسبة حول الأثار السلبية للاندفاعية، والإدمان وخسائر الانتكاسـات المتكررة بعد التعافي، وذللك بين فئة الثباب والمراهقين، نظراً لأنهم أكثر الفئات المستهدفة للوقوع في دائرة التعاطي.

\section{zall}

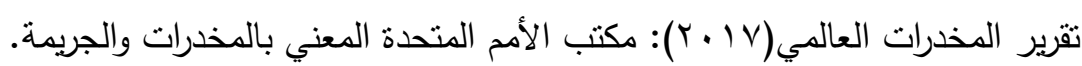
حمدي الفرماي (ع (99)): الأساليب المعرفية بين النظرية والبحث، القاهرة : مكتبة الأنجلو

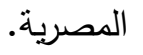

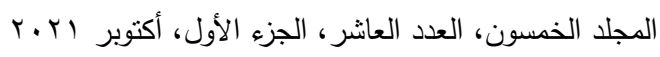

$$
\begin{aligned}
& \text { النزقيم الدولي } \\
& \text { التزقيم الدولي الموحد الإلكتروني 3178-2636-2كإل }
\end{aligned}
$$


سهام أبو عطيه، آلاء الثايلة: فاعلية الإرشاد الجمعي المستتد إلى العلاج الجدلي السلوكي

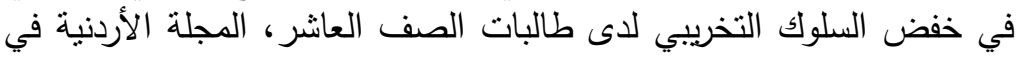

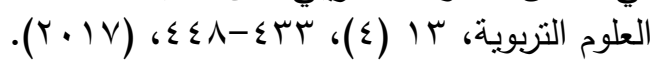

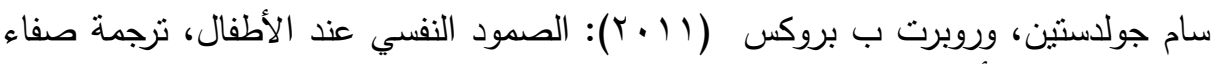

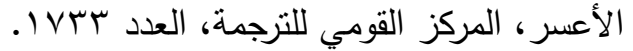

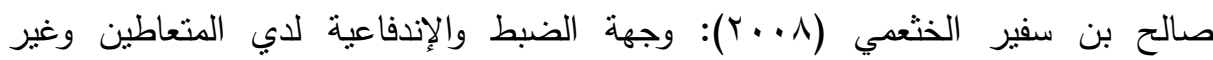

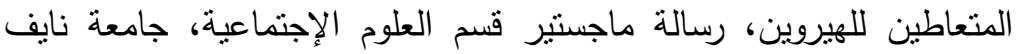

$$
\text { للعلوم الأمنية. }
$$

عبد الفتاح الخواجة: فاعلية برنامج العلاج العقلاني الانفعالي السلوكي في خفض مستوى الكاني

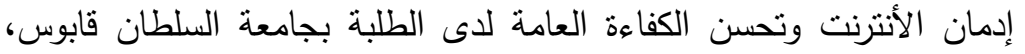

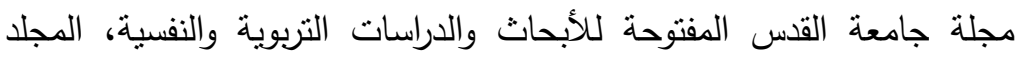

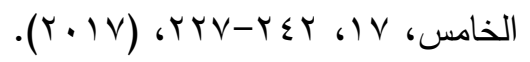

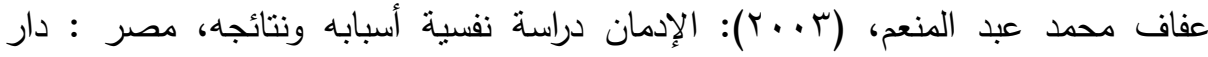

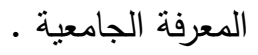

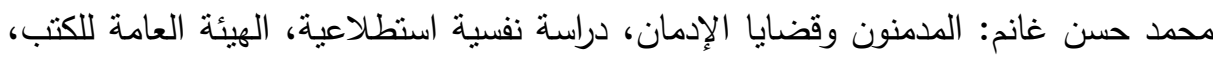

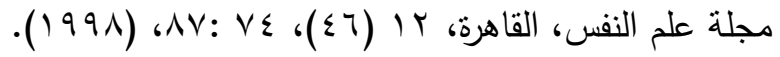

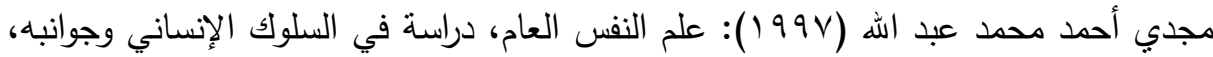
الإسكندرية، مصر ، دار المعرفة الجامعية.

Bechara, A: The Neurology of Social Cognition. Brain, a journal of neurology , 125, 8,1673-1675, (2002).

C.Roncero.L.Rodríguez-CintasC.DaigreF.GideoniN.MartínezLunC.BarralA.EgidoC.LópezJ.AlvarósE.Ros(2011):

Impulsivity and addiction severity in cocaine, cocaine and heroin and heroin dependent patients measured by BIS-11 and Europasi, European Psychiatry, 26, 1, Page 97.

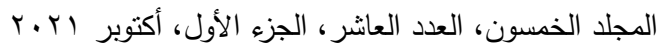

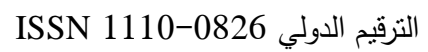

$$
\begin{aligned}
& \text { الترقيم الدولي الموحد الإكتروني 3178-2636 }
\end{aligned}
$$




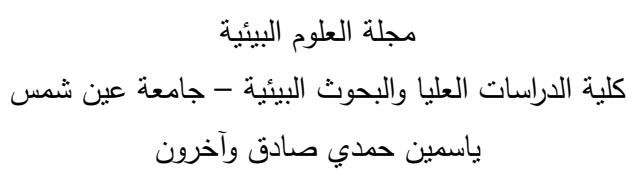

Clark, W.R. and Grunstein, M. (2004): Are you hardwired? : The role of genes in human behavior. New York: Oxford University Press.

Dalley, J.W., Everitt, B.J., Robbins, T.W., (2011): Impulsivity, compulsivity, and top-down cognitive control. Neuron 67, 680-694.

Dickman, J, (1990): Functional and dysfunctional impulsivity: Personality and cognitive correlates. Journal of Personality and Social Psychology, 58(1), 95-102.

Esra Cicek, I, Ibrahim Eren, Erdinc cicek, Basak Demirel, Nalan Varsak, October (2017): impulsiveness and aggression in male heroin addicts : A prospective controlled study, 117, $1-5$

Judith, Herbert, w: Ardes, L and David, p (2001): the patient recovering from alcohol or drug addiction special issues for the anesthesiology isn't, international Anesthesia Research socity, 92(6), p 1601-1608

Krous, S., L., Guttornson, U., Leifman, H., Arpa, S., Molinara, S., \& Monshouwer, K (2016): ESPAD Report 2015, Results from the European school survey project on alcohol and other drugs, Luxembourg, publications office of the Europeah union.

Kristine Romer Thomsen, Mette Buhl Caileseh, Morten Hesse, Timo Lenmann Kvamme, Mlchael Mlbjerg pederseh, Mads Uffe Pedeksen: Impulsivity traits and addiction related behaviors is youth, Journal of Behavioral Addictions, 7, 2, 317- 330, (2018).

Steinberg, L, Elizabeth, C, Marie, B, Sandra, G\& Jennifer, W (2008): Age differences in sensation seeking and impulsivity as

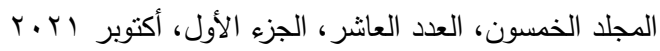

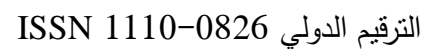

$$
\begin{aligned}
& \text { التزقيم الدولي الموحد الإلكتروني 3178-2636 }
\end{aligned}
$$




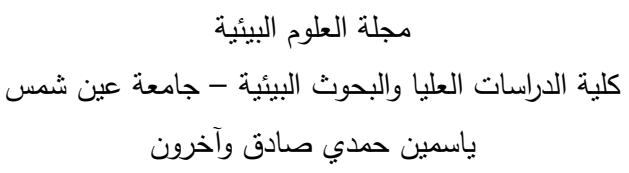

indexed by behavior and self-report, Department of Psychology, Temple University, 44(6), 1764- 1778.

Vassileva, J, Raul Gohzalez Antoine Bechara, Eileen M.Martin, December (2007): Are all drug addicts impulsive? Effects of antisociality and extent of multidrug use on cognitive and motor impulsivity, Addictive Behaviors ،32(12), 30713076.

Vassileva, J, Stefan Georgiev, Eileen Martin, Raul Gonzalez, Laura Segale, (2011): Psychopathic heroin addicts are not uniformly impaired across neurocognitive domains of impulsivity, Drug and

\title{
A COUNSELING PROGRAM FOR REDUCING IMPULSIVE BEHAVIOR FOR A SAMPLE OF ADDICTS
}

\author{
Yasmen H. Sadek ${ }^{(1)}$;Asma A. Ibrahim ${ }^{(2)}$; \\ Ahmed H. Mohamed ${ }^{(3)}$ and Talat B. Hakeem ${ }^{(4)}$
}

1) Post Grad. Student, Faculty of Environmental Studies and Research, Ain Shams University 2) Faculty of Girls, Ain Shams University 3) Faculty of Education, Helwan University 4) Faculty of Arts Ain, Shams University

\footnotetext{
ABSTRACT

The current study aimed to prepare a program to reduce impulsive behavior for a sample of addicts, The total study sample consisted of (16) male addicts at Abbasiya mental health hospital, whose ages ranged from (20: 35) years, and they were divided into two 330

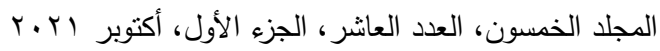

$$
\begin{aligned}
& \text { النزقيم الدولي } \\
& \text { الترقيم الدولي الموحد الإلكتروني 3178-2636 }
\end{aligned}
$$




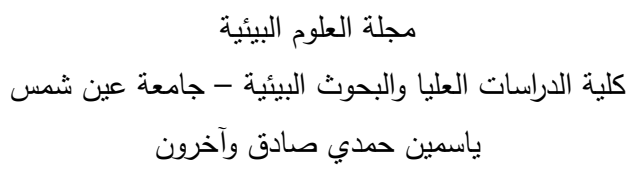

experimental and control groups equally, the researcher used in this study the following tools: Impulsive behavior scale (prepared by: the researchers), A counseling program to reduce impulsive behavior (prepared by: the researchers), the researchers used in this study the experimental method, the results showed statistically significant differences between averages degrees of the experimental group and the control group in impulsive behavior scale in favor of the experimental group after applying the program and statistically significant differences between averages degrees of the experimental group in the pre and post measurement on the impulsive behavior in favor of the post measurement, however the results doesn't show statistically significant differences between averages degrees of the experimental group on the impulsive behavior in the post and follow up measurement.

Keywords: Addicts, Impulsive behavior, A counseling Program

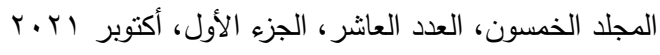

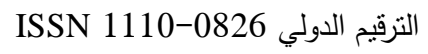

$$
\begin{aligned}
& \text { الترقيم الدولي الموحد الإلكتروني 3178-2636 }
\end{aligned}
$$

